\title{
CUSTO DA IRRIGAÇÃO DO CAFEEIRO EM DIFERENTES TIPOS DE EQUIPAMENTO E TAMANHOS DE ÁREA
}

Gustavo Haddad Souza Vieira1, Everardo Chartuni Mantovani², Antônio Alves Soares³, David Rolando Palomino Montes $^{4}$, Fernando França da Cunha ${ }^{5}$

\section{RESUMO}

Objetivou-se, neste trabalho, determinar os custos unitários totais de diferentes sistemas de irrigação na cultura cafeeira, em quatro tamanhos de área, em um período de dez anos, e indicar o método de irrigação mais economicamente viável em função do tamanho da área. Os sistemas de irrigação estudados foram: aspersão em malha, aspersão convencional fixo, aspersão convencional portátil e gotejamento. Os quatro tamanhos de área foram: 3, 10, 20 e 50 ha. Para estimativa dos custos de implantação dos sistemas de irrigação na cultura do cafeeiro, consideraram-se quatro projetos para cada sistema de irrigação, totalizando 16 projetos. Ao final das simulações, obtiveram-se os custos totais, por meio da soma dos custos fixos e variáveis de cada sistema, que foram, então, comparados entre si. Os custos unitários totais dos sistemas de irrigação foram, respectivamente, para as áreas de 3, 10, 20 e 50 ha: gotejamento $(\mathrm{R} \$ 20.234,44 ; \mathrm{R} \$ 1$ 19.079,92; $\mathrm{R} \$ 18.349,12 \mathrm{e}$ $\mathrm{R} \$ 20.901,66) ;$ aspersão em malha ( $\mathrm{R} \$ 23.654,10 ; \mathrm{R} \$ 20.586,41 ; \mathrm{R} \$ 19.848,13$ e $\mathrm{R} \$ 20,506.51$ ); aspersão fixa ( $\mathrm{R} \$$ $21.730,85 ; \mathrm{R} \$ 20.670,43 ; \mathrm{R} \$ 22.762,07$ e $\mathrm{R} \$ 22.272,58)$ e aspersão convencional portátil (R\$ 32.386,36; R \$ 33.164,37; $\mathrm{R} \$ 34.341,63$ e R \$35.961.53). O método de irrigação mais economicamente viável neste estudo foi o gotejamento.

Palavras-chave: análise econômica, irrigação por aspersão, irrigação localizada.

\section{ABSTRACT \\ IRRIGATION COSTS OF COFFEE CULTIVATION IN DIFFERENT TYPES OF EQUIPMENT AND AREA SIZES}

The objective of this study was to determine the full costs of different irrigation systems of the coffee crop in four sizes of area in a period of 10 years and the method of irrigation more economically viable in the size of the area. Irrigation systems were: net sprinkler, fixed sprinkler, portable sprinkler and drip irrigation. The four area sizes were: 3, 10, 20 and 50 ha. To estimate the costs of implementation of irrigation systems in the coffee crop, it was designed four projects for each irrigation system, a total of 16 projects. At the end of the simulations it obtained the total costs with the sum of fixed and variable costs of each system and then compared. The unit costs of irrigation were, respectively, for the areas of 3,10 , 20 and 50 ha: drip irrigation ( $\mathrm{R} \$ 20.234,44 ; \mathrm{R} \$ 19.079,92 ; \mathrm{R} \$ 18.349,12$ and $\mathrm{R} \$ 20.901,66$ ), net sprinkler ( $\mathrm{R} \$ 23.654,10$, $\mathrm{R} \$ 20.586,41$ and $\mathrm{R} \$ 19.848,13$ and $\mathrm{R} \$ 20.506,51$ ), fixed sprinkler (R\$21.730,85; R\$20.670,43; R $22.762,07$ and $\mathrm{R} \$$ $22.272,58$ ) and portable sprinkler ( $R \$ 32.386,36$ and $R \$ 33.164,37$ and $R \$ 34.341,63$ and $R \$ 35.961,53)$. The irrigation method more economically feasible in this study was the drip irrigation.

Keywords: economic analysis, sprinkle irrigation, drip irrigation, coffee crop.

\section{Recebido para publicação em 28/10/2009. Aprovado em 05/05/2010}

1- Doutorando em Engenharia Agrícola/UFV, Viçosa, MG, Bolsista do PIQDTec/CAPES, Prof. do IFES, campus Santa Teresa, ES, e-mail: ghsv2000@yahoo.com.br

2- Engenheiro Agrícola, Prof. Titular da UFV, DEA, Viçosa, MG, e-mail: everardo@ufv.br

3- Engenheiro Agrícola, Prof. Titular da UFV, DEA, Viçosa, MG, e-mail: aasoares@ufv.br

4- Agrônomo, Doutorando na UFV, DEA, Viçosa, MG, e-mail: d_palomino13@hotmail.com

5- Prof. da Univale e da Unipac, e-mail: cunhaff@yahoo.com.br 


\section{INTRODUÇ̃̃O}

Com o surgimento de novas tecnologias disponíveis para a cafeicultura irrigada, associado à ocorrência de períodos secos prolongados em maior incidência e ao aparecimento de novos cultivares mais produtivos e mais responsivos ao fornecimento hídrico, houve maior interesse dos cafeicultores em adotar a irrigação em suas lavouras. Porém, nesse processo de crescimento da cafeicultura irrigada observa-se, na maioria dos projetos, que não há um planejamento nem mesmo um acompanhamento dos custos envolvidos no sistema de produção.

Determinar a viabilidade de um empreendimento que se inicia é fundamental para o seu sucesso. Muitos fatores podem influenciar o agricultor na tomada de decisão sobre irrigar ou não suas culturas. A irrigação é uma tecnologia que requer investimentos representativos e está associada à utilização intensiva de insumos, tornando importante a análise econômica dos componentes envolvidos no sistema (SILVA et al., 2003).

Não se deve fazer irrigação pelo simples prazer de dizer que se está fazendo agricultura irrigada, mas, sim, com o objetivo de aumentar o lucro, com o aumento da produção e da qualidade, ou de incorporar à agricultura áreas que não seriam possíveis de se cultivar sem o uso da irrigação. $\mathrm{O}$ planejamento e operação de um sistema de irrigação devem ser baseados nos objetivos e nas condições em que se executará o sistema. Em regiões onde a água é fator limitante, o objetivo deve ser a obtenção da máxima produção por unidade de água aplicada. Em outras condições, o objetivo pode ser a obtenção de máxima produção por unidade de área cultivada, custo de mão de obra ou de energia consumida (BERNARDO, 1995).

A escolha do método de irrigação a ser utilizado depende de vários fatores. Nenhum sistema de irrigação é aplicável ou vantajoso em todas as circunstâncias. Tipo de terreno e cultura, disponibidade e custo de energia e algumas vezes a qualidade da água auxiliarão na decisão de qual sistema deve ser empregado (CUENCA, 1989).

Em muitos casos, o agricultor opta pelo sistema que possui maior difusão comercial na região de cultivo e, ainda, é influenciado pelas informações repassadas pelo comerciante, que, geralmente, possui como objetivo principal o lucro imediato. Raramente, informações sobre o consumo de energia elétrica do sistema de bombeamento, custos de mão de obra operacional, manutenção do sistema e outros são devidamente explicitados ao irrigante, comumente pelo desconhecimento desses fatores por parte dos projetistas e comerciantes.

Frizzone e Andrade Jr. (2005) não recomendam selecionar um projeto apenas porque seus benefícios líquidos são positivos. Esses autores recomendam também estudar os projetos alternativos possíveis, com seus correspondentes custos e benefícios.

Um fator que leva o irrigante a escolher qual o equipamento de irrigação a ser adquirido é o seu custo inicial de implantação. Mas, geralmente, o sistema de menor custo de aquisição não apresenta os menores custos operacionais. Para que se possa selecionar adequadamente, deve-se fazer simulação dos custos fixos e variáveis oriundos do sistema de irrigação adotado e do seu manejo.

De acordo com Thompson et al. (1983), os custos anuais de irrigação devem incluir todos os custos associados com a compra do equipamento, operação e manutenção do sistema de irrigação.

O custo fixo é composto da depreciação de cada componente do sistema de irrigação e dos juros aplicados sobre o capital investido na implantação, operacionalização e manutenção do sistema. $\mathrm{O}$ custo variável inclui as despesas de operacionalização, como energia, combustível, mão de obra etc; despesas de manutenção como reposições e consertos; e eventuais, como perdas por falhas do sistema, e acréscimos ou decréscimos no manejo da lavoura, de acordo com cada sistema adotado (FERNANDES et al., 2008).

Frizzone e Andrade Jr. (2005) dividem os custos fixos em custos diretos (aquisição de equipamentos, construção de obras, instalações elétricas e sistematização) e indiretos (custos de engenharia, de empreitada, de reservas de contingência, de remuneração do capital investido, seguros, taxas e impostos). Os custos variáveis são divididos em custos financeiros, custos de operação, manutenção e reposição e ainda os tributos e seguros.

Keller e Bliesner (1990) citam que os dados econômicos requeridos para uma análise econômica da irrigação dividem-se em duas categorias: dependente do sistema e dependente do local. A primeira categoria inclui os custos dos componentes do sistema, vida útil dos componentes, mão de obra, energia e manutenção. A segunda categoria inclui taxa de juros, custo de mão de obra, inflação da energia, taxas de propriedade, custos da água, valor da terra e retorno devido à irrigação para cada cultura. 
Os critérios econômicos para avaliar se há viabilidade ou não da irrigação do cafeeiro, em uma dada região, ainda são muito vagos, sendo que inúmeros autores recomendam a adoção da irrigação levando-se em consideração apenas os custos de implantação (SOUZA, 2001).

Desta forma, objetivou-se com o presente trabalho: determinar os custos unitários totais de quatro sistemas de irrigação (aspersão em malha, aspersão convencional portátil, aspersão convencional fixo e gotejamento) na cultura do café, em quatro tamanhos de área $(3,10,20$ e 50 ha), em um período de dez anos, e indicar o método de irrigação mais economicamente viável em função do tamanho da área.

\section{MATERIAL E MÉTODOS}

Os sistemas de irrigação estudados foram: aspersão em malha, aspersão convencional fixo, aspersão convencional portátil e gotejamento. Para estimativa dos custos de implantação dos sistemas de irrigação na cultura do café, consideraram-se áreas com quatro tamanhos distintos $(3,10,20$ e 50 ha), totalizando 16 projetos. Esses projetos foram instalados em terreno plano e regular, utilizando água de boa qualidade para irrigação, de modo a facilitar a comparação dos dados deste trabalho com outros.

Os equipamentos foram divididos em: tubulação (incluindo conexões, válvulas e tubos), estruturas (abrigo para a motobomba e cabeçal de controle), motobombas (bombas, motores elétricos e dispositivos de partida), emissores (aspersores e tubogotejadores), filtros (filtro de disco e injetores venturi) e extras (cola para PVC, lixa e fita vedarosca).

A demanda hídrica da cultura foi estimada com uso do software Irriplus $^{\odot}$ para a cidade de Araguari, MG, latitude $18^{\circ} 39^{\prime}$ 'Selongitude $48^{\circ} 11^{\prime} \mathrm{O}$, utilizando dados climáticos do INMET, determinando-se a evapotranspiração de referência (ETo) com a Equação de Penman e Monteith (ALLEN et al., 1998), que, multiplicada pelos coeficientes culturais (Kc) para as diferentes fases da cultura, forneceram os valores da evapotranspiração da cultura (ETc) para os sistema de irrigação por aspersão. Para os sistema de irrigação por gotejamento, multiplicouse a ETo pelo Kc e pelo coeficiente por causa da irrigação localizada $(\mathrm{K} 1)$, fornecendo os valores da evapotranspiração da cultura irrigada por gotejamento (ETg) (BERNARDO, 1995).

A seleção dos emissores foi feita com referência na demanda hídrica do sistema solo-plantaatmosfera, de modo a suprir as necessidades de consumo de água pela cultura, considerandose irrigação suplementar com probabilidade de ocorrência de precipitação igual a $75 \%$.

As características consideradas para determinação da demanda hídrica foram: capacidade de campo $\left(0_{\text {cc }}=0,40 \mathrm{~m}^{3} \mathrm{~m}^{-3}\right)$, ponto de murchamento permanente da planta $\left(0_{\mathrm{pm}}=0,223 \mathrm{~m}^{3} \mathrm{~m}^{-3}\right)$, do solo $\left(\mathrm{d}_{\mathrm{s}}=1,2 \mathrm{~g} \mathrm{~cm}^{-3}\right)$, fator de disponibilidade hídrica ( $\mathrm{f}$ $=0,4)$, profundidade efetiva do sistema radicular ( $\mathrm{z}$ $=45 \mathrm{~cm}$ ), eficiência dos sistemas de irrigação por aspersão $(\mathrm{Ea}=85 \%)$, eficiência dos sistemas de irrigação por gotejamento $(\mathrm{Ea}=90 \%)$, percentagem de área molhada $(\mathrm{pw}=32,5 \%)$, percentagem de área sombreada pela cultura em fase de produção plena após o quarto ano (50\%). O coeficiente devido à irrigação localizada $(\mathrm{Kl})$ foi determinado pelo método de Fereres (MANTOVANI et al., 2007), utilizando o maior valor considerado entre área sombreada ou molhada.

A cultura considerada para os cálculos foi o cafeeiro arábica (Coffeea arabica), plantado em espaçamento de $4 \mathrm{~m}$ entre fileiras de plantio por $0,5 \mathrm{~m}$ entre plantas dentro da fileira, com coeficiente cultural $(\mathrm{Kc})$ variando de 0,45 (início do desenvolvimento) a 1,00 (quarto ano em diante) (FERNANDES et al., 2008).

Para o dimensionamento das tubulações principais, considerou-se o intervalo de velocidade admissível entre 1,0 e $2,0 \mathrm{~m} \mathrm{~s}^{-1}$, com posterior determinação da perda de carga com as Equações propostas por Keller e Bliesner (1990).

As linhas laterais (para sistemas de aspersão convencional) e linhas secundárias (para sistemas de gotejamento) foram dimensionadas considerando a perda de carga fictícia, pelo método de Christiansen (KELLER; BLIESNER, 1990), em tubulações com múltiplas saídas.

Em sistemas de aspersão, foi permitida variação máxima de $20 \%$ da pressão de serviço do aspersor na linha lateral $(\Delta \mathrm{P}=20 \% \mathrm{Ps})$. Para sistemas de gotejamento, foi permitida variação máxima no setor igual a $30 \%$ da pressão de serviço do gotejador. A pressão no início da linha lateral foi calculada considerando-se a situação em que se demanda maior valor de pressão. Selecionouse o conjunto motobomba com catálogos dos fabricantes, identificando os modelos que atenderam 
à vazão e à altura manométrica total do sistema de irrigação.

Os valores de compra dos equipamentos foram consultados no comércio de Viçosa, Janaúba e Belo Horizonte/MG, em Reais (R\$). Considerou-se, neste projeto, como equipamentos, as tubulações, emissores, conexões, conjunto motobomba, filtros e válvulas. Foram computados os custos fixos de depreciação dos componentes do sistema (DC) e dos juros sobre o capital investido (JC); e os custos variáveis de energia elétrica (CEE), de mão de obra (CMO) e de manutenção dos componentes dos sistemas (CMC).

Para o cálculo dos custos de depreciação dos equipamentos, foi utilizada a Equação 1 (FERNANDES et al., 2008):

$$
D C=\frac{[(V A C)-(0,2 V A C)]}{V U}
$$

em que,

$\mathrm{DC}=$ depreciação do componente do sistema ( $\mathrm{R} \$)$; $\mathrm{VAC}=$ valor de aquisição do componente $(\mathrm{R} \$)$; $\mathrm{VAC}=$ valor residual ou de sucata $(\mathrm{R} \$)$; e $\mathrm{VU}=$ vida útil (anos).

O valor residual ou de sucata foi calculado por 20 $\%$ do valor de compra do componente. Os valores de vida útil dos equipamentos foram obtidos de Fernandes et al. (2008) e Frizzone e Andrade Jr. (2005).

O custo de oportunidade foi medido com o custo dos juros do mercado financeiro sobre o capital investido, conforme sugerem Frizzone e Andrade Jr. (2005).

O custo dos juros sobre o capital investido (JC) foi calculado considerando-se a taxa de rendimentos da poupança, que, no Brasil, está em torno de 7,2 $\%$ ao ano, incidindo sobre o valor de aquisição dos equipamentos (Investimento inicial), conforme Equação 2:

$$
\mathrm{JC}=\mathrm{TAJ} \times \mathrm{VAE}
$$

em que,

$\mathrm{JC}=$ juros sobre o capital investido (R\$);

TAJ $=$ taxa anual de juros (\%) e

$\mathrm{VAE}=$ valor de aquisição dos equipamentos $(\mathrm{R} \$)$.
Os custos de energia elétrica foram obtidos pela soma da demanda mais a multiplicação das horas anuais de funcionamento do equipamento, pelo valor cobrado do kWh pela companhia de fornecimento e pela potência exigida do conjunto motobomba, considerando-se as eficiências da bomba e do motor elétrico, conforme sugerido na Equação 3. Foi considerada a utilização da Tarifa Verde, Grupo A3a, com irrigação noturna fora do horário de ponta em período seco (CEMIG, 2009):

$$
\mathrm{CEE}=\mathrm{DEM}+(\mathrm{Pot} \times \mathrm{T} \times \mathrm{C})
$$

em que,

$\mathrm{CEE}=$ custo anual de energia elétrica $(\mathrm{R} \$)$;

$\mathrm{DEM}=$ demanda contratada $(\mathrm{R} \$)$;

Pot $=$ potência do conjunto motobomba $(\mathrm{kW})$;

$\mathrm{T}=$ tempo anual de funcionamento do sistema (h); e

$\mathrm{C}=$ valor cobrado pelo kilowatt hora $(\mathrm{R} \$)$.

O tempo de funcionamento anual do sistema de irrigação foi simulado utilizando-se o software Irriplus ${ }^{\odot}$, considerando atendimento a $60 \%$ da demanda hídrica da cultura e desconsiderando os meses de junho e julho, referentes ao período de póscolheita, quando não se faz uso da irrigação pelos irrigantes da região referente ao estudo. Respeitaramse as fases de desenvolvimento da cultura, de modo que o tempo de funcionamento do sistema fosse progressivo do primeiro ao quarto ano, tornando-se constante deste ponto em diante.

Os custos de mão de obra e manutenção dos diferentes sistemas foram computados utilizando-se dados de Fernandes et al. (2008) e Keller e Bliesner (1990), com as Equações 4 e 5, respectivamente:

$$
\begin{aligned}
& \mathrm{CMO}=\mathrm{AS} \times \mathrm{EMS} \times \mathrm{SM} \\
& \mathrm{CMC}=\mathrm{VPM} \times \mathrm{VAC}
\end{aligned}
$$

em que,

$\mathrm{CMO}=$ custo anual de mão de obra (R\$);

$\mathrm{AS}$ = área do sistema (ha);

EMS = exigência média de mão de obra do sistema (número de homens por ha);

$\mathrm{SM}=$ salário mínimo atual brasileiro, incluindo os encargos tributários (R\$);

$\mathrm{CMC}=$ custo anual de manutenção dos componentes 
do sistema (R\$);

$\mathrm{VPM}=$ valor percentual médio anual para manutenção dos componentes do sistema (decimal); e

$\mathrm{VAC}=$ valor de aquisição do componente $(\mathrm{R} \$)$.

Ao valor do salário mínimo, foram adicionados os encargos referentes a esse salário, considerando como fonte pagadora o proprietário rural pessoa jurídica, consistindo de acidente de trabalho $(0,1 \%)$, INSS Previdência Social $(2,5$ $\%)$, SENAR $(0,25 \%), 13^{\circ}$ salário (1/12), férias $(1 / 12)$, adicional de $1 / 3$ sobre as férias $(1 / 12 / 3)$, FGTS (8\%), rescisão salarial (4\%), INSS ( 8 $\%$ e contribuição sindical (R \$ 15,00 por ano), somando um adicional de 42,56\% incidentes sobre o salário mínimo.

Os valores de exigência de mão de obra dos sistemas (EMS) utilizados foram: aspersão convencional portátil $\left(0,25\right.$ homem ha- $\left.{ }^{-1}\right)$, aspersão convencional fixa $\left(0,05\right.$ homem ha- $\left.{ }^{-1}\right)$, aspersão em malha $(0,1$ homem ha-1) e gotejamento $(0,04$ homem ha-1). Os custos anuais de manutenção dos componentes (CMC) utilizados foram: tubulações enterradas $(0,5 \%)$, tubulações em superfície (1\%), estruturas $(1,5 \%)$, motobombas $(6 \%)$, emissores (7\%) e filtros (8\%) (FERNANDES et al., 2008; KELLER \& BLIESNER, 1990).

Todos os cálculos foram realizados em planilhas eletrônicas. Foram adicionados $5 \%$ sobre o valor dos custos variáveis de modo a prever uma reserva de contingência, que pode ser utilizada em casos emergenciais como falhas humanas, mecânicas ou do sistema (FERNANDES et al., 2008). Os custos referentes ao consumo de água não foram levados em consideração, visto que, na região referente à simulação ainda não se faz cobrança pelo uso da água.

Ao final das simulações, foram obtidos os custos totais, pela soma dos custos fixos (implantação, depreciação e juros sobre o capital) e variáveis (energia elétrica, mão de obra e manutenção) de cada sistema, e, então, comparados entre si para fornecer um indicativo do sistema de menor custo para as condições estudadas.

\section{RESULTADOS E DISCUSSÃO}

Os resultados obtidos nas simulações são apresentados detalhadamente nos Quadros que seguem, com valores em Reais (R\$), com cotação obtida no mês de julho de 2009. Para fins de comparações futuras, cotou-se o valor do dólar americano no dia 03 de julho de 2009, que apresentou relação de US\$1,00 $=\mathrm{R} \$ 1,95$.

Os custos totais de implantação dos equipamentos de irrigação, incluindo tubulações, estruturas, motobombas, emissores e filtros são apresentados no Quadro 1. O sistema de irrigação que apresentou os menores custos de implantação foi o de aspersão convencional, seguido de aspersão em malha, aspersão fixa e gotejamento, para áreas de até 20 ha. Para a área de 50 ha, o sistema de menor custo foi o de malha e o mais caro foi o de aspersão fixa. Nota-se que para todos os sistemas, há uma tendência de aumento do custo unitário $\left(\mathrm{R} \$ \mathrm{ha}^{-1}\right)$ com o aumento do tamanho da área. Desse modo, ao se projetar sistemas de irrigação para áreas maiores, deve-se pensar em sistemas modulares, ou seja, dividir o projeto em módulos independentes.

Um aspecto que merece atenção no dimensionamento de projetos de irrigação é identificar qual dos itens que compõem o sistema possui maior custo. Um resumo do custo unitário $\left(\mathrm{R} \$ \mathrm{ha}^{-1}\right)$ dos componentes do sistema é apresentado no Quadro 2 .

Observa-se que as tubulações são os componentes mais caros dos sistemas. Isso ajuda a explicar o aumento do custo unitário $\left(\mathrm{R} \$ \mathrm{ha}^{-1}\right)$ com o

Quadro 1. Custos de implantação $\left(\mathrm{R} \$ \mathrm{ha}^{-1}\right)$ dos equipamentos de irrigação

\begin{tabular}{ccccc}
\hline $\begin{array}{c}\text { Área } \\
\text { (ha) }\end{array}$ & $\begin{array}{c}\text { Aspersão } \\
\text { Conv. }\end{array}$ & $\begin{array}{c}\text { Asp. } \\
\text { Malha }\end{array}$ & $\begin{array}{c}\text { Asp. } \\
\text { Fixa }\end{array}$ & Gotejamento \\
\hline 3 & $2.613,82$ & $3.621,79$ & $4.260,38$ & $4.547,31$ \\
10 & $2.716,96$ & $3.316,52$ & $4.219,21$ & $4.498,63$ \\
20 & $2.835,28$ & $3.357,77$ & $4.779,91$ & $4.496,58$ \\
50 & $4.011,61$ & $3.964,87$ & $5.190,97$ & $5.115,58$ \\
\hline
\end{tabular}


Quadro 2. Componentes dos sistemas de irrigação e sua participação no custo final (R \$) de implantação

\begin{tabular}{|c|c|c|c|c|c|c|c|c|}
\hline & Área (ha) & Tubulações & Estruturas & Motobombas & Emissores & Filtros & Extra & Total \\
\hline \multirow{4}{*}{ 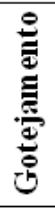 } & G3 & $1.367,35$ & 333,33 & 832,14 & $2.153,33$ & 171,22 & 23,27 & $4.880,64$ \\
\hline & G10 & $1.590,87$ & 200,00 & 535,40 & $2.121,60$ & 243,78 & 6,98 & $4.698,63$ \\
\hline & G20 & $1.671,77$ & 100,00 & 486,45 & $2.121,60$ & 210,17 & 6,59 & $4.596,58$ \\
\hline & G50 & $1.812,28$ & 40,00 & 586,62 & $2.545,92$ & 168,13 & 2,64 & $5.155,58$ \\
\hline \multirow{4}{*}{$\begin{array}{l}\text { 它 } \\
\text { 窝 }\end{array}$} & $\mathrm{AC} 3$ & $1.673,95$ & 333,33 & 832,14 & 95,20 & 0,00 & 12,53 & $2.947,16$ \\
\hline & AC10 & $2.077,84$ & 200,00 & 535,40 & 99,96 & 0,00 & 3,76 & $2.916,96$ \\
\hline & $\mathrm{AC} 20$ & $2.194,74$ & 100,00 & 538,70 & 99,96 & 0,00 & 1,88 & $2.935,28$ \\
\hline & AC50 & $3.324,28$ & 40,00 & 586,62 & 99,96 & 0,00 & 0,75 & $4.051,61$ \\
\hline \multirow{4}{*}{ 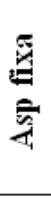 } & $\mathrm{AF} 3$ & $2.803,25$ & 333,33 & 921,00 & 523,60 & 0,00 & 12,53 & $4.593,72$ \\
\hline & $\mathrm{AF} 10$ & $3.126,97$ & 200,00 & 538,70 & 549,78 & 0,00 & 3,76 & $4.419,21$ \\
\hline & $\mathrm{AF} 20$ & $3.576,85$ & 100,00 & 651,40 & 549,78 & 0,00 & 1,88 & $4.879,91$ \\
\hline & AF50 & $4.038,11$ & 40,00 & 586,62 & 565,49 & 0,00 & 0,75 & $5.230,97$ \\
\hline \multirow{4}{*}{ 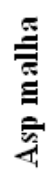 } & AM3 & $2.588,14$ & 333,33 & 921,14 & 89,25 & 0,00 & 23,27 & $3.955,12$ \\
\hline & AM10 & $2.670,39$ & 200,00 & 535,40 & 91,04 & 0,00 & 19,70 & $3.516,52$ \\
\hline & AM20 & $2.763,44$ & 100,00 & 486,45 & 91,04 & 0,00 & 16,85 & $3.457,77$ \\
\hline & AM50 & $3.467,32$ & 40,00 & 385,54 & 98,53 & 0,00 & 13,48 & $4.004,87$ \\
\hline
\end{tabular}

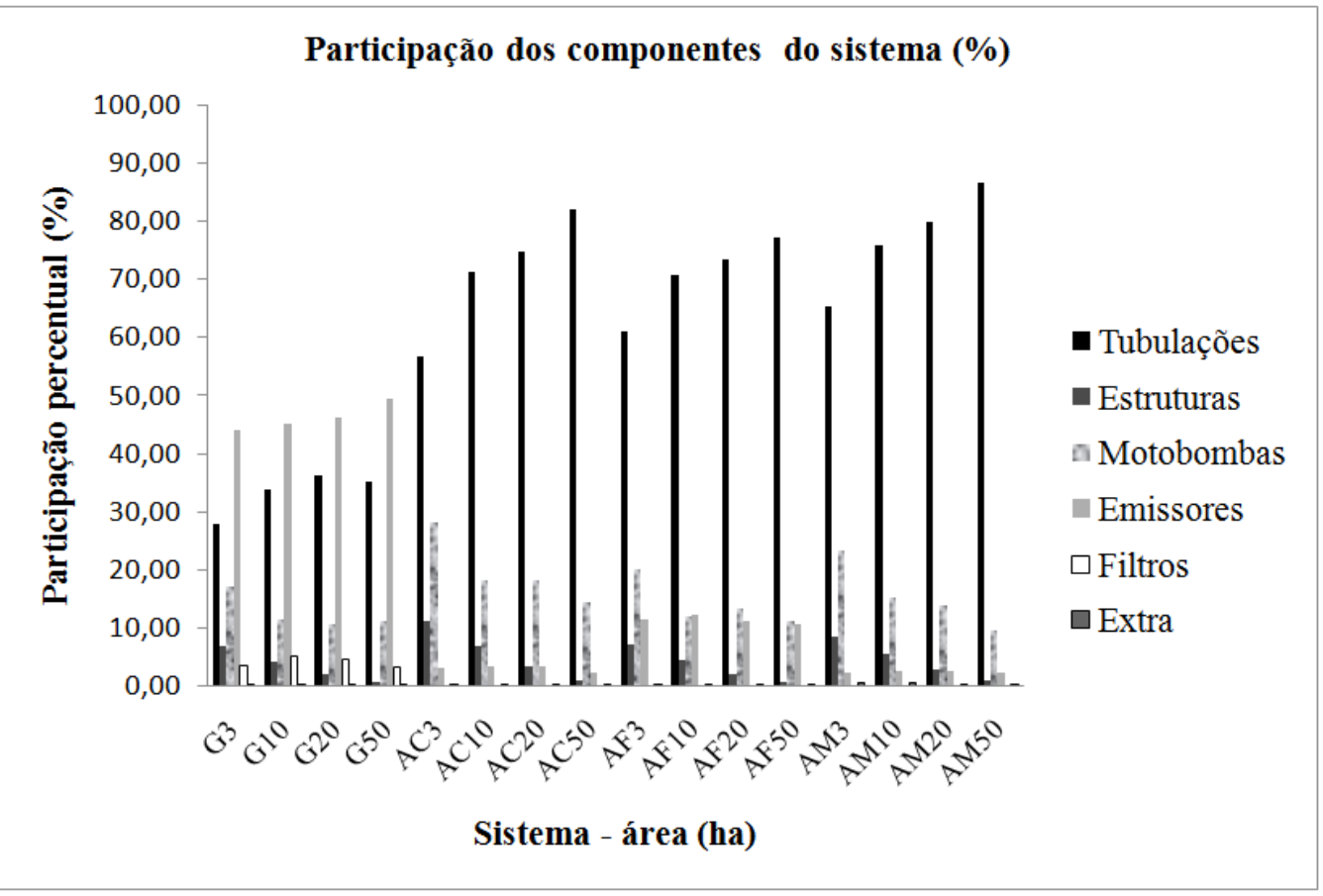

Figura 1. Participação percentual dos componentes do sistema de irrigação no seu custo final de implantação.

aumento da área irrigada. À medida que se aumenta o diâmetro das tubulações, obtém-se um aumento exponencial de seus preços. Os valores referentes aos filtros apresentaram valor igual a zero para os sistemas de aspersão, uma vez que não se faz necessária sua utilização com estes equipamentos. Para o sistema de gotejamento, observaram-se valores bem distintos, se comparados com os demais sistemas. Isso ocorreu porque foram considerados como emissores os tubogotejadores, os quais, em outra análise, poderiam ser considerados como tubulações.

Os percentuais da participação dos componentes dos sistemas de irrigação no custo final de implantação são apresentados na Figura 1.

Observa-se uma tendência de aumento do percentual de participação das tubulações no custo final de implantação com o aumento da área. 
Especificamente para o gotejamento, os emissores apresentaram o maior percentual, no entanto, devese levar em consideração que os tubogotejadores aqui apresentados como emissores, são tubulações com emissores integrados.

Com as motobombas, observou-se o contrário, visto que, à medida que se aumentou a área irrigada, observou-se diminuição do seu percentual de participação nos custos. O mesmo observou-se para as estruturas. Os emissores apresentaram a mesma tendência em sistemas de gotejamento, não mostrando diferenças nos sistemas de aspersão. Para os filtros, não se observou tendência definida de aumento ou redução no percentual de participação dos custos com o aumento da área irrigada.

Os custos fixos totais (implantação, depreciação e juros sobre o capital investido) estão apresentados no Quadro 3.

Observam-se, no Quadro 3, as mesmas relações observadas no Quadro 1, onde são apresentados os custos de aquisição dos equipamentos. Há evidência para o sistema de gotejamento, que apresentou maiores valores em relação aos outros métodos. Isso se deve à sua menor vida útil, que eleva o valor da depreciação.

Os juros sobre o capital investido, neste caso, representam o custo de oportunidade do investimento, conforme descrito por Frizzone e Andrade Jr. (2005). Ao se analisar a possibilidade de compra de equipamentos de irrigação, devem-se considerar os custos fixos totais e não somente os custos de aquisição dos equipamentos.

Os custos de energia elétrica por hectare irrigado são apresentados no Quadro 4, com simulações feitas para irrigação suplementar, considerando as chuvas e para irrigação total, para o período de dez anos.

O sistema de irrigação que apresentou maior consumo unitário de energia $\left(\mathrm{R} \$ \mathrm{ha}^{-1}\right)$ foi o sistema por aspersão fixa para a área de 20 ha. Observouse, para a aspersão convencional e para a fixa, tendência de queda do consumo com o aumento da área irrigada, porém, com maior consumo na área de 20 ha, possivelmente pela utilização de duas motobombas em paralelo. Para a aspersão em malha, a menor área (3 ha) apresentou o maior consumo unitário, com tendência de queda do consumo com o aumento da área. Para o gotejamento, a área de 20 ha apresentou o menor consumo unitário e a de 50 ha o maior, não apresentando tendência de aumento ou queda do consumo com o aumento da área irrigada.

Quadro 3. Custos fixos anuais totais $\left(\mathrm{R} \$ \mathrm{ha}^{-1} \mathrm{ano}^{-1}\right)$ dos sistemas de irrigação

\begin{tabular}{ccccc}
\hline $\begin{array}{c}\text { Área } \\
\text { (ha) }\end{array}$ & $\begin{array}{c}\text { Aspersão } \\
\text { Convencional }\end{array}$ & $\begin{array}{c}\text { Aspersão } \\
\text { Malha }\end{array}$ & $\begin{array}{c}\text { Aspersão } \\
\text { Fixa }\end{array}$ & Gotejamento \\
\hline 3 & 377,12 & 423,23 & 511,61 & 637,38 \\
10 & 385,69 & 373,92 & 480,31 & 570,30 \\
20 & 391,07 & 366,92 & 539,72 & 562,03 \\
50 & 546,34 & 423,24 & 576,10 & 645,64 \\
\hline
\end{tabular}

Quadro 4. Custos de energia elétrica por hectare irrigado para o período de dez anos

\begin{tabular}{ccccc}
\hline Área (ha) & Aspersão Conv. & Asp. Malha & Asp. Fixa & Gotejamento \\
\hline \multicolumn{5}{c}{ Irrigação Suplementar } \\
\hline 3 & $4.997,06$ & $6.717,06$ & $6.794,07$ & $3.373,94$ \\
10 & $5.873,98$ & $4.827,15$ & $6.519,89$ & $3.629,15$ \\
20 & $6.980,44$ & $4.257,38$ & $7.537,95$ & $3.116,69$ \\
50 & $5.798,56$ & $3.834,56$ & $6.145,50$ & $3.910,59$ \\
\hline \multicolumn{5}{c}{ Irrigação Total } \\
\hline 3 & $7.156,77$ & $9.620,13$ & $9.730,43$ & $6.125,80$ \\
20 & $8.412,68$ & $6.913,42$ & $9.337,75$ & $6.589,17$ \\
50 & $9.997,35$ & $6.097,40$ & $10.795,82$ & $5.658,73$ \\
\hline
\end{tabular}


Comparando-se os valores simulados para irrigação total e suplementar, observa-se aumento do custo de energia elétrica de $42,22 \%$ para os sistemas de aspersão e de $81,56 \%$ para o gotejamento. Esse detalhe deve ser observado na previsão da demanda hídrica da cultura para fins de dimensionamento, uma vez que as chuvas ocorrem, para a região em estudo, nos meses de maior demanda. Se esse detalhe não for considerado no dimensionamento, ocorrerá superdimensionamento dos sistemas de irrigação.

Os custos unitários $\left(\mathrm{R} \$ \mathrm{ha}^{-1}\right)$ referentes à mão de obra demandada nos quatro tipos de sistemas de irrigação em dez anos são apresentados na Figura 2.

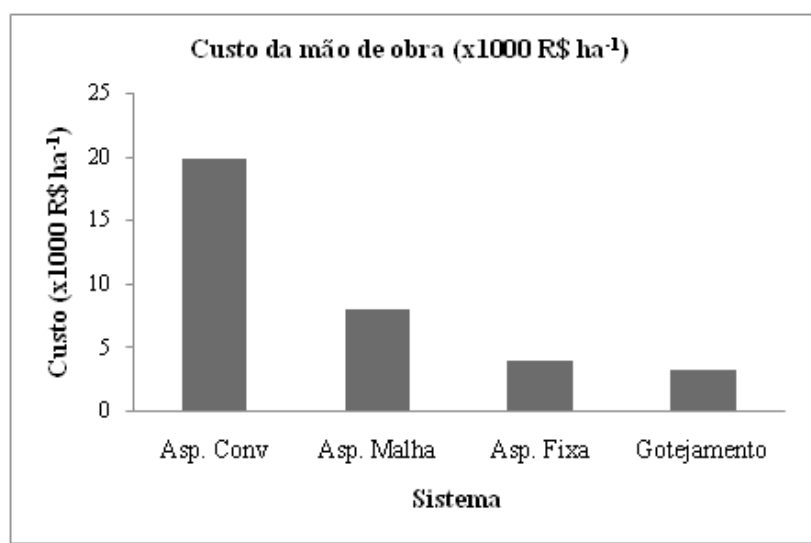

Figura 2. Custos unitários de mão de obra $\left(\mathrm{R} \$ \mathrm{ha}^{-1}\right)$ dos sistemas de irrigação em 10 anos.

O sistema de irrigação que apresentou maior custo de mão de obra foi o sistema por aspersão convencional, seguido da aspersão em malha, aspersão fixa e gotejamento. Não foram comparados neste trabalho os custos de mão de obra entre os tamanhos de área, visto que, para um mesmo sistema, os custos unitários são iguais para os diferentes tamanhos de área.

Os custos unitários de manutenção $\left(\mathrm{R} \$\right.$ ha $\left.^{-1}\right)$ para os quatro tamanhos de área são apresentados na Figura 3. O sistema de gotejamento foi o que apresentou maior custo unitário de manutenção, seguido da aspersão fixa, da aspersão convencional e da aspersão em malha. Observou-se uma tendência de redução dos custos de manutenção com o aumento da área até 20 ha, com aumento expressivo para a área de 50 ha.

Somando-se os custos fixos (implantação, depreciação e juros sobre o capital) e variáveis (energia elétrica, mão de obra e manutenção) de cada sistema, obtiveram-se os custos unitários totais, que são apresentados na Figura 4.

O sistema de irrigação com maior custo total foi a irrigação por aspersão convencional portátil, com tendência de aumento do custo com o aumento da área. A aspersão em malha apresentou o segundo maior custo em menores áreas, com tendência de redução com o aumento da área irrigada. A aspersão fixa apresentou leve tendência de aumento do custo com o aumento da área. Já o gotejamento apresentou os menores custos totais dentre os sistemas estudados, com tendência de decréscimo dos custos com o aumento da área até 20 ha, com aumento expressivo para a área de 50 ha.

Ao adquirir um equipamento de irrigação o irrigante deve estar atento a uma análise do custo total que a irrigação vai lhe proporcionar. Geralmente, analisase somente o custo de aquisição dos equipamentos (SOUZA, 2001) e, se este for o único parâmetro analisado na decisão de qual método se adotar, podese escolher erroneamente, como citado por Silva et al. (2003).

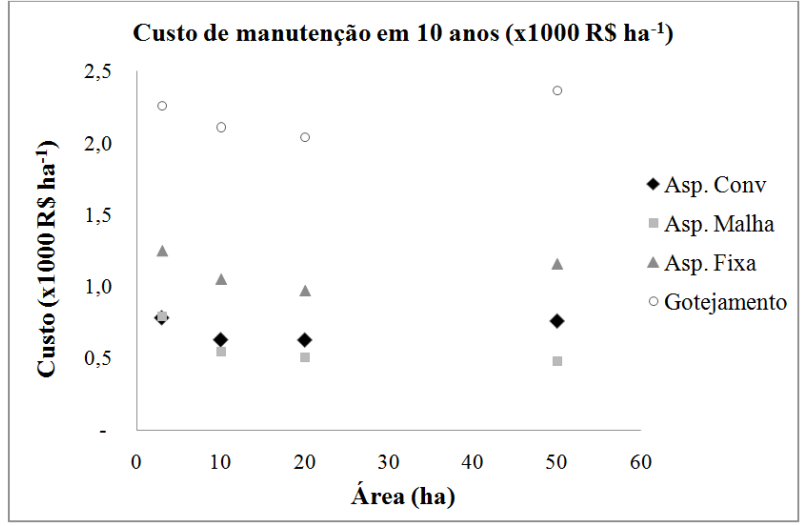

Figura 3. Custos unitários de manutenção $\left(\mathrm{R} \$\right.$ ha $\left.^{-1}\right)$ em um período de dez anos dos sistemas de irrigação para os quatro tamanhos de área.

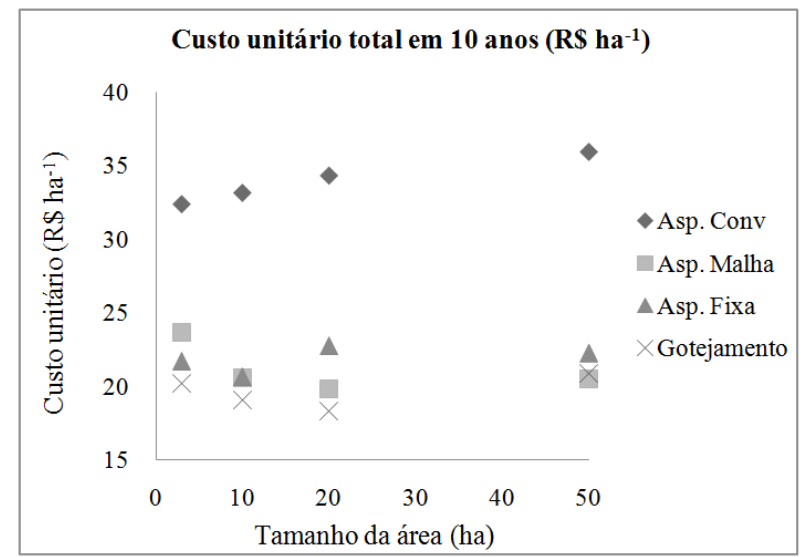

Figura 4. Custos unitários totais $\left(\mathrm{R} \$ \mathrm{ha}^{-1}\right)$ em um período de dez anos dos sistemas de irrigação para os diferentes tamanhos de área. 


\section{CONCLUSÕES}

- Os custos unitários totais dos sistemas de irrigação foram, respectivamente, para as áreas de 3,10, 20 e 50 ha: gotejamento (R\$ $20.234,44 ; \mathrm{R} \$ 19.079,92 ; \mathrm{R} \$ 18.349,12 \mathrm{e}$ R\$ 20.901,66); aspersão em malha (R\$ 23. 654,$10 ; \mathrm{R} \$ 20.586,41 ; \mathrm{R} \$ 19.848,13$ e $\mathrm{R} \$$ 20.506,51); aspersão fixa ( $\mathrm{R} \$ 21.730,85 ; \mathrm{R} \$$ $20.670,43 ; \mathrm{R} \$ 22.762,07$ e $\mathrm{R} \$ 22.272,58)$ e aspersão convencional portátil (R\$ 32.386,36; $\mathrm{R} \$ 33.164,37$; $\mathrm{R} \$ 34.341,63$ e $\mathrm{R} \$ 35.961,53)$; e

- O método de irrigação mais economicamente viável neste estudo foi o gotejamento.

\section{REFERÊNCIAS BIBLIOGRÁFICAS}

ALLEN, R.G.; PEREIRA, L.S.; RAES, D.; SMITH, M. Crop evapotranspiration - guidelines for computing crop water requirements. Rome: FAO, 1998. 318p.

BERNARDO, S. Manual de Irrigação. 6. ed. Viçosa: UFV, 1995. 657p.

CEMIG. Tarifas e serviços. Disponível em: $<$ atendimentovirtual.cemig.com.br/portal/ avisos/?txtCod=1>. Acesso em: 17 abr. 2009.

CUENCA, R.H. Irrigation system design: engineering approach. New Jersey: Prentice Hall, 1989. 552p.
FERNANDES, A.L.T.; SANTINATO, R.; FERNANDES, D.R. Irrigação na cultura do café. 2. ed. Uberaba: O Lutador, 2008. 476p.

FRIZZONE, J.A.; ANDRADE Júnior, A.S. de. Planejamento de irrigação: análise de decisão de investimento. Brasília: EMBRAPA, 2005. 626p.

KELLER, J.; BLIESNER, R. D. Sprinkle and trickle irrigation. New York: Avibook, 1990. 652p.

MANTOVANI,E.C.; BERNARDO, S.; PALARETTI, L.F. Irrigação: princípios e métodos. Viçosa: UFV. 2. ed, 2007.358p.

Silva, A.L. da.; FARIA, M.A.de. REIS, R.P. Viabilidade técnico econômica do uso do sistema de irrigação por gotejamento na cultura do cafeeiro. Revista Brasileira de Engenharia Agrícola e Ambiental, Campina Grande, PB, v.7, n.1, p.37-44.

SOUZA, J.L.M. de. Modelo para análise de risco econômico aplicado ao planejamento de projetos de irrigação para cultura do cafeeiro. 2001. 253f. (Tese) (Doutorado em Agronomia) - Esalq/USP, Piracicaba, SP, 2001. Disponível em: <http://www.teses.usp.br/ teses/disponiveis/11/11143/tde-11102001-180056/>. Acesso em: 26 mar. 2009.

THOMPSON, G.T.; SPIESS, L.B.; KRIDER, J.N. Farm resources and system selection. In: JENSEN, M.E. (Ed.). Design and operation of farm irrigation systems. St. Joseph: ASAE, 1983. p.45-76. 